\title{
Cochrane in $\operatorname{CORR}^{\circledR}$ : Arthroplasty Versus Fusion in Single-level Cervical Degenerative Disc Disease
}

\author{
Nathan Evaniew MD, Kim Madden Bsc, \\ Mohit Bhandari MD, PhD, FRCSC
}

Received: 14 August 2013/Accepted: 4 September 2013/Published online: 28 September 2013

(C) The Association of Bone and Joint Surgeons (B) 2013

\section{Importance of the Topic}

Cervical spondylosis is a common age-related degenerative condition that affects the vertebrae, intervertebral discs, and associated ligaments of the cervical spine [17]. By age $60,95 \%$ of men and $70 \%$ of women show radiographic evidence of cervical spondylosis [9], and approximately

(Boselie TFM, Willems PC, van Mameren H, de Bie R, Benzel EC, van Santbrink H. Arthroplasty versus fusion in single-level cervical degenerative disc disease. Cochrane Database of Systematic Reviews 2012, Issue 9. Art. No.: CD009173. DOI: 10.1002/14651858. CD009173.pub2. Copyright The Cochrane Collaboration, Published by John Wiley \& Sons, Ltd., reproduced with permission.) A Note from the Editor-in-Chief: I am pleased to announce the partnership between $\mathrm{CORR}^{\mathbb{R}}$, The Cochrane Collaboration ${ }^{\mathbb{R}}$, and McMaster University's Evidence-Based Orthopaedics Group for a new column, called Cochrane in $\mathrm{CORR}^{\circledR}$. In it, we will identify an abstract originally published in The Cochrane Library that we think is especially important, and Dr. Mohit Bhandari, our Deputy Editor for Evidence-Based Orthopaedics, and his colleagues from McMaster University will provide expert perspective on it.

The author certifies that he, or a member of his immediate family, has no funding or commercial associations (eg, consultancies, stock ownership, equity interest, patent/licensing arrangements, etc) that might pose a conflict of interest in connection with the submitted article.

All ICMJE Conflict of Interest Forms for authors and Clinical Orthopaedics and Related Research ${ }^{\circledR}$ editors and board members are on file with the publication and can be viewed on request.

The opinions expressed are those of the writers, and do not reflect the opinion or policy of $C O R R^{\mathbb{R}}$ or the Association of Bone and Joint Surgeons ${ }^{\circledR}$.

Cochrane Reviews are regularly updated as new evidence emerges and in response to feedback, and The Cochrane Library (http://www. thecochranelibrary.com) should be consulted for the most recent version of the review.

This Cochrane in $\operatorname{CORR}^{\circledR}$ column refers to the abstract available at: DOI: 10.1002/14651858.CD009173.pub2.
8\% have MRI evidence of early spinal cord compression [13]. Patients may present with varying combinations of radiculopathy, progressive myelopathy, and axial neck pain [6]. For those who fail to improve with conservative management, decompression through anterior cervical discectomy and fusion is an established and effective surgical option [8]. Following fusion, however, compensatory changes at adjacent spinal levels may lead to accelerated degeneration and recurrence of symptoms. Estimates of the clinical importance and prevalence of adjacent segment disease are highly variable [8].

Cervical intervertebral disc arthroplasty is an alternative procedure intended to prevent adjacent segment disease by maintaining spinal motion. Biomechanical, clinical, and radiographic data suggest its effectiveness, but long-term data are lacking, and the benefits of motion-preservation remain theoretical $[1,4,7,10,18,19]$. This systematic review and meta-analysis sought to determine whether arthroplasty is as least as successful as fusion at relieving pain and preventing neurological decline at short-term followup.

N. Evaniew, M. Bhandari

Division of Orthopaedics, McMaster University, Hamilton, ON, Canada

N. Evaniew ( $₫)$

Division of Orthopaedics, Center for Evidence-Based

Orthopaedics, 293 Wellington Street North, Suite 110, Hamilton,

ON L8L 8E7, Canada

e-mail: nathan.evaniew@medportal.ca

K. Madden, M. Bhandari

Department of Clinical Epidemiology and Biostatistics, McMaster University, Hamilton, ON, Canada 


\section{Upon Closer Inspection}

While there were statistically significant differences between groups for several of the primary outcomes (favoring disc replacement), the effect sizes were small, and they probably were not clinically meaningful. Effect sizes this small probably do not justify changes in patient care, particularly where a new technology is concerned, as there are important unanswered questions about costs and longer-term durability with respect to disc arthroplasty that would appear to overshadow these small statistical differences. Minimal Important Differences (MIDs) are the smallest effects that patients perceive as beneficial enough to justify a change in their management, and they can be determined for functional outcome scales [11]. In this review, the authors used MIDs for the Neck Disability Index and the Numerical Rating Scale that were established for patients with neck pain [14]. None of the effect sizes for the primary outcomes exceeded these MIDs. Specific MIDs for patients with radicular pain or myelopathy were not available.

Of the nine included studies, eight were industry-sponsored, and outcome assessors, patients, and caregivers were not blinded in any included study. Large studies of new devices involve complex economic and logistic challenges, but industry-sponsorship is believed to bias results towards pro-industry findings [2]. It is possible that the favorable treatment effects for the cervical arthroplasty groups were overestimated in most of the studies. To move forward, researchers must emphasize transparent reporting of study funding, study design, and study management, as well as the processes of manuscript preparation and criteria for authorship [3]. Patients, caregivers, and outcome assessors should be blinded to minimize further bias [12], and surgeon bias can be controlled through expertise-based designs [15].

\section{Take-Home Messages}

Methodological strengths of this review included a detailed literature search, a thorough assessment of bias among primary articles, and multiple sensitivity analyses to examine internal validity. The authors considered the effects of missing data, study heterogeneity, reporting bias, and clinical differences between subgroups, and they acknowledged the limitations due to short follow-up, small sample sizes, and inconsistent outcome measurements. This study did not include summary estimates for complications or adverse events. Using the Grading of Recommendations Assessment, Development and Evaluation (GRADE) system [5], the overall quality of evidence was low to moderate.

Fusion and arthroplasty following anterior decompression for symptomatic cervical spondylosis appear to provide equivalent clinical outcomes in the short-term, but future well-designed trials with large sample sizes, rigorous methodology, and long-term followup are warranted. The potential benefits of motion-preservation and reduced adjacent segment disease are of substantial interest to patients and their surgeons, and an evidence-based approach is paramount. Outcomes between specific implants and surgical techniques, as well as between subgroups of patients with varying symptoms of prior treatments should also be examined, and the inclusion of cost-effectiveness analyses will refine the practical implementation of this technology [16]. 
Appendix

\section{Arthroplasty versus fusion in single-level cervical degenerative disc disease (Review)}

Boselie TFM, Willems PC, van Mameren H, de Bie R, Benzel EC, van Santbrink H

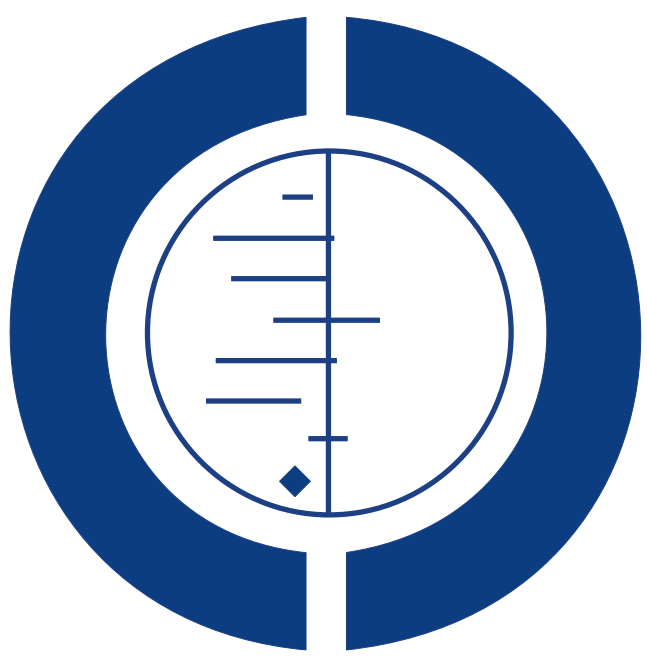

\section{THE COCHRANE COLLABORATION ${ }^{\circledR}$}

This is a reprint of a Cochrane review, prepared and maintained by The Cochrane Collaboration and published in The Cochrane Library 2012, Issue 10

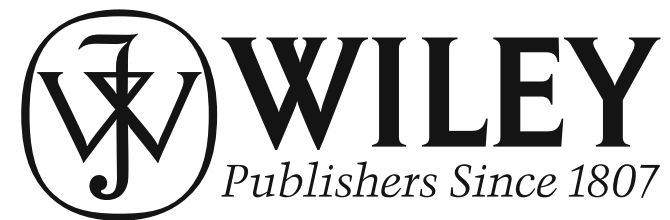

Arthroplasty versus fusion in single-level cervical degenerative disc disease (Review)

Copyright $\odot 2012$ The Cochrane Collaboration. Published by John Wiley \& Sons, Ltd. 
[Intervention Review]

\title{
Arthroplasty versus fusion in single-level cervical degenerative disc disease
}

\author{
Toon FM Boselie ${ }^{1}$, Paul C Willems ${ }^{2}$, Henk van Mameren ${ }^{3}$, Rob de Bie ${ }^{3}$, Edward C Benzel ${ }^{4}$, Henk van Santbrink ${ }^{1}$ \\ ${ }^{1}$ Department of Neurosurgery, Maastricht University Medical Centre, Maastricht, Netherlands. ${ }^{2}$ Department of Orthopaedics, Maas- \\ tricht University Medical Centre, Maastricht, Netherlands. ${ }^{3}$ Department of Epidemiology, Maastricht University, Maastricht, Nether- \\ lands. ${ }^{4}$ Department of Neurosurgery, Cleveland Clinic Foundation, Cleveland, OH, USA
}

Contact address: Toon FM Boselie, Department of Neurosurgery, Maastricht University Medical Centre, P. Debeyelaan 25, Maastricht, 6229 HX, Netherlands. T.Boselie@MUMC.nl.

Editorial group: Cochrane Back Group.

Publication status and date: Edited (no change to conclusions), published in Issue 10, 2012.

Review content assessed as up-to-date: 26 March 2012.

Citation: Boselie TFM, Willems PC, van Mameren H, de Bie R, Benzel EC, van Santbrink H. Arthroplasty versus fusion in single-level cervical degenerative disc disease. Cochrane Database of Systematic Reviews 2012, Issue 9. Art. No.: CD009173. DOI: 10.1002/14651858.CD009173.pub2.

Copyright (C) 2012 The Cochrane Collaboration. Published by John Wiley \& Sons, Ltd.

\section{A B S T R A C T}

\section{Background}

There is ongoing debate about whether fusion or arthroplasty is superior in the treatment of single level cervical degenerative disc disease. Mainly because the intended advantage of arthroplasty over fusion, that is, the prevention of symptoms due to adjacent segment degeneration in the long term, is not confirmed yet. Until sufficient long-term results become available, it is important to know whether results of one of the two treatments are superior to the other in the first one to two years.

\section{Objectives}

To assess the effects of arthroplasty versus fusion for radiculopathy or myelopathy, or both due to single level cervical degenerative disc disease.

\section{Search methods}

We searched the following databases for randomised controlled trials (RCTs): CENTRAL (The Cochrane Library 2011, Issue 2), MEDLINE, EMBASE, and EBMR. Additionally, we searched the System for Information on Grey Literature (SIGLE), subheading Biological and Medical Sciences, the US Food and Drug Administration (FDA) database on medical devices, and Clinicaltrials.gov to identify trials in progress. We also screened the reference list of all selected papers. Date of search: 25 May 2011.

\section{Selection criteria}

We included RCTs that directly compared any type of cervical fusion with any type of arthroplasty, with at least one year of followup. Primary outcomes were arm pain, neck pain, neck-related functional status, patient satisfaction, neurological outcome, and global health status. Secondary outcomes were the presence of (radiological) fusion, revision surgery at the treated level, secondary surgery on adjacent levels, segmental mobility of treated and adjacent levels, and work status.

Arthroplasty versus fusion in single-level cervical degenerative disc disease (Review)

Copyright @ 2012 The Cochrane Collaboration. Published by John Wiley \& Sons, Ltd. 


\section{Data collection and analysis}

Study selection was performed independently by three review authors, and 'Risk of bias' assessment and data extraction were performed by two review authors. In case of missing data or insufficient information for a judgement about risk of bias, we tried to contact the study authors or the study sponsor. The data were entered into RevMan by one review author and subsequently checked by a second review author. We assessed the quality of evidence using GRADE. We analysed heterogeneity and performed sensitivity analyses for the pooled analyses.

\section{Main results}

We included nine studies (2400 participants), five of which had a low risk of bias. Eight of these studies were industry sponsored. The most important results showed low-quality evidence for a small but significant difference in alleviation of arm pain at one to two years in favour of arthroplasty (mean difference (MD) -1.54; $95 \%$ confidence interval (CI) -2.86 to $-0.22 ; 100$-point scale). A small study effect could not be ruled out for this outcome in the sensitivity analyses. This means that smaller studies (or small published subsets of larger studies) showed larger differences for this outcome, which may indicate publication bias. Also, moderate-quality evidence showed a small difference in neck-related functional status at one to two years in favour of arthroplasty (MD $-2.79 ; 95 \%$ CI -4.73 to 0.85; 100-point scale) and a small difference in neurological outcome in favour of arthroplasty (risk ratio (RR) $1.05 ; 95 \%$ CI 1.01 to 1.09). These two outcomes were robust to sensitivity analyses. For none of the primary outcomes, was a clinically relevant difference shown. Additionally, there was high-quality evidence for a large, statistically significant difference in segmental mobility at one to two years (measured as degrees segmental range of motion) at the treated level (MD 6.90; 95\% CI 5.45 to 8.35). There was low-quality evidence that there was no statistically significant difference in secondary surgery at the adjacent levels at one to two years (RR 0.60 ; $95 \%$ CI 0.35 to 1.02 ). The latter was not robust to sensitivity analyses.

\section{Authors' conclusions}

There was a tendency for clinical results to be in favour of arthroplasty; often these were statistically significant. However, differences in effect size were invariably small and not clinically relevant for all primary outcomes. Significance was often gained or lost in the varying sensitivity analyses, probably owing to the relatively small number of studies, in combination with the small differences that were found. Given the fact that all of the included studies were not blinded, this could be due to patient or carer expectations. However, at this time both treatments can be seen as valid options with respect to results at a maximum of one to two years. Given the current absence of truly long-term results, use of these mobile disc prostheses should still be limited to clinical trials.

There was high-quality evidence that the goal of preservation of segmental mobility in arthroplasty was met. A statistically significant effect on the incidence of secondary symptoms at adjacent levels, the primary goal of arthroplasty over fusion, was not found at one to two years. If there was a protective effect, this should become clearer over time. A future update, when studies with 'truly long-term' results (five years or more) become available, should focus on this issue.

\section{PLAIN LANGUAGE SUMMARY}

\section{Is there a benefit of implanting a mobile disc prosthesis over traditional fusion surgery for treatment of a herniated disc in the} neck?

A herniated disc in the neck often causes radiating pain, numbness, and weakness in muscles of the neck, shoulders, arms, and hands. It may also lead to symptoms in the trunk and legs.

When there is no or insufficient relief of symptoms with non-surgical treatment, surgery can be an option. Traditional 'fusion' surgery involves fusion of the two bones of the spine (the vertebrae) that form the disc space. Motion between these two vertebrae is then no longer possible.

It has been suggested that this may cause the adjacent parts of the spine to become more mobile, as compensation. This in turn might accelerate normal wear and tear in these parts of the spine, which could lead to new symptoms. At present this is not confirmed.

Mobile disc prostheses have been introduced in an effort to reduce the amount of new symptoms at the longer term after surgery by preserving motion between the vertebrae involved. Long-term results are not available yet. However, it is important to know whether disc arthroplasty is at least as effective as fusion in relieving symptoms, the primary aim of surgery.

In this review we have searched for all studies in which the patient receives one of these two possible treatments at random.

Arthroplasty versus fusion in single-level cervical degenerative disc disease (Review)

Copyright @ 2012 The Cochrane Collaboration. Published by John Wiley \& Sons, Ltd. 
We identified nine studies (2400 participants), and considered five of these to have high methodological quality. This review shows that patients who were treated with a mobile disc prosthesis had less pain radiating to the arm one to two years after surgery, and less disability owing to these complaints. However, the actual differences were very small, only between 1 and 5 points on a 100 -point scale. The overall quality of the evidence was low to moderate, which means that including new studies in future years could change these conclusions. The conclusion that mobility is in fact preserved after placement of a mobile disc prosthesis, compared to traditional 'fusion' surgery, is unlikely to change. Whether this preserved mobility will lead to fewer new symptoms in the future is uncertain based on results for the first one to two years after surgery.

Therefore, a comparison of results in the long term (five years or more) will be made when more studies with long-term results have become available. 


\section{References}

1. Anderson PA, Sasso RC, Hipp J, Norvell DC, Raich A, Hashimoto R. Kinematics of the cervical adjacent segments after disc arthroplasty compared with anterior discectomy and fusion: A systematic review and meta-analysis. Spine (Phila Pa 1976). 2012;37(22 Suppl):S85-95.

2. Bhandari M, Busse JW, Jackowski D, Montori VM, Schunemann H, Sprague S, Mears D, Schemitsch EH, Heels-Ansdell D, Devereaux PJ. Association between industry funding and statistically significant pro-industry findings in medical and surgical randomized trials. CMAJ. 2004;170:477-480.

3. Bhandari M, Jonsson A, Buhren V. Conducting industry-partnered trials in orthopaedic surgery. Injury. 2006;37:361-366.

4. Boselie TF, Willems PC, van Mameren H, de Bie R, Benzel EC, van Santbrink H. Arthroplasty versus fusion in single-level cervical degenerative disc disease. Cochrane Database Syst Rev. 2012;9:CD009173.

5. Brozek JL, Akl EA, Alonso-Coello P, Lang D, Jaeschke R, Williams JW, Phillips B, Lelgemann M, Lethaby A, Bousquet J, Guyat GH, Schünemann HJ, GRADE Working Group. Grading quality of evidence and strength of recommendations in clinical practice guidelines. Part 1 of 3 . An overview of the GRADE approach and grading quality of evidence about interventions. Allergy. 2009;64:669-677.

6. Cason GW, Herkowitz HN. Cervical intervertebral disc replacement. J Bone Joint Surg Am. 2013;95:279-285.

7. Chen J, Fan SW, Wang XW, Yuan W. Motion analysis of singlelevel cervical total disc arthroplasty: A meta-analysis. Orthop Surg. 2012;4:94-100.

8. Cho SK, Riew KD. Adjacent segment disease following cervical spine surgery. J Am Acad Orthop Surg. 2013;21:3-11.

9. Gore DR, Sepic SB, Gardner GM. Roentgenographic findings of the cervical spine in asymptomatic people. Spine (Phila Pa 1976). 1986;11:521-524.
10. Harrod CC, Hilibrand AS, Fischer DJ, Skelly AC. Adjacent segment pathology following cervical motion-sparing procedures or devices compared with fusion surgery: A systematic review. Spine (Phila Pa 1976). 2012;37(22 Suppl):S96-S112.

11. Jaeschke R, Singer J, Guyatt GH. Measurement of health status. Ascertaining the minimal clinically important difference. Control Clin Trials. 1989;10:407-415.

12. Karanicolas PJ, Bhandari M, Taromi B, Akl EA, Bassler D, Alonso-Coello P, Rigau D, Bryant D, Smith SE, Walter SD, Guyatt GH. Blinding of outcomes in trials of orthopaedic trauma: An opportunity to enhance the validity of clinical trials. $J$ Bone Joint Surg Am. 2008;90:1026-1033.

13. Matsumoto M, Fujimura Y, Suzuki N, Nishi Y, Nakamura M, Yabe Y, Shiga H. MRI of cervical intervertebral discs in asymptomatic subjects. J Bone Joint Surg Br. 1998;80:19-24.

14. Pool JJ, Ostelo RW, Hoving JL, Bouter LM, de Vet HC. Minimal clinically important change of the neck disability index and the numerical rating scale for patients with neck pain. Spine (Phila Pa 1976). 2007;32:3047-3051.

15. Scholtes VA, Nijman TH, van Beers L, Devereaux PJ, Poolman RW. Emerging designs in orthopaedics: Expertise-based randomized controlled trials. J Bone Joint Surg Am. 2012;94 Suppl 1:24-28.

16. Sprague S, Quigley L, Adili A, Bhandari M. Understanding cost effectiveness: Money matters? J Long Term Eff Med Implants. 2007; 17:145-152.

17. Tracy JA, Bartleson JD. Cervical spondylotic myelopathy. Neurologist. 2010;16:176-187.

18. Yang B, Li H, Zhang T, He X, Xu S. The incidence of adjacent segment degeneration after cervical disc arthroplasty (CDA): A meta analysis of randomized controlled trials. PLoS One. 2012;7:e35032.

19. Yu L, Song Y, Yang X, Lv C. Systematic review and metaanalysis of randomized controlled trials: Comparison of total disk replacement with anterior cervical decompression and fusion. Orthopedics. 2011;34:e651-658. 